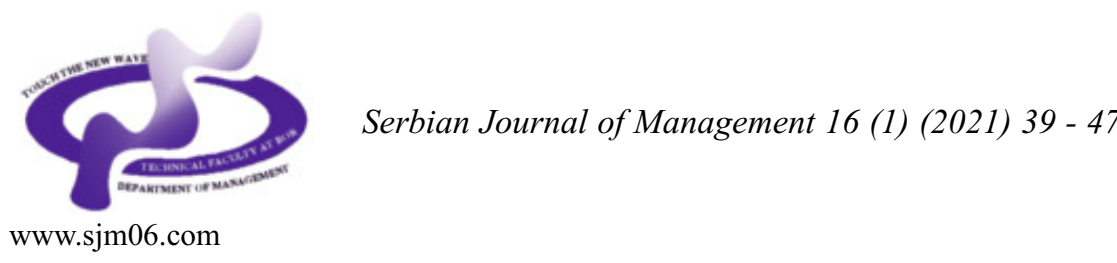

Serbian

Journal

\title{
LAPLACE, HANSEN-SARGENT AND BEVERIDGE-NELSON A NOTE TOWARDS UNIFIED BUSINESS APPLICATION
}

\author{
Vladimir Andrića* and Sanja Nenadovićb

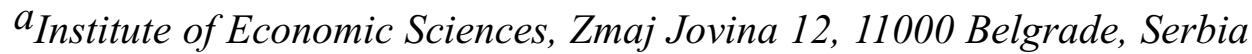

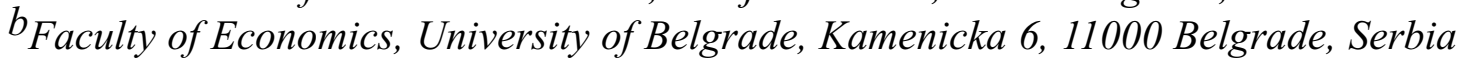

(Received 16 February 2021; accepted 14 March 2021)

\begin{abstract}
The paper derives the equivalence condition between the Beveridge-Nelson decomposition and the Hansen-Sargent prediction formula in continuous time using Laplace transforms. The results presented show how the Hansen-Sargent prediction formula is relevant not just for present value discounting but also for the trend-cycle decomposition of cash flow streams in corporate finance.
\end{abstract}

Keywords: Beveridge-Nelson decomposition, Hansen-Sargent prediction formula, Laplace transforms, cash flows

\section{INTRODUCTION}

Beveridge and Nelson (1981) introduce a general procedure for the decomposition of nonstationary time series into a permanent (trend) random walk with a drift component and transitory (cyclical) stationary meanzero component. On the other hand, Hansen and Sargent (1981) derive a prediction formula for infinite geometrically declining sums of expected future variables' values, which plays a pivotal role in asset pricing literature. Contrary to the Hansen-Sargent formula, which deals with expected future variables' values, the Beveridge-Nelson decomposition depends only on past data and therefore is computable in real-time.

This paper contributes to the existing literature by demonstrating how the Beveridge-Nelson decomposition is just a special case of the Hansen Sargent prediction formula. The paper relies heavily on the contributions outlined in Cochrane (2012) with several crucial extensions: first, the formal mathematical background for the application of Laplace transforms in connection with stochastic processes is provided, which could be of potential use to business managers, especially in light of somewhat limited use of these techniques in

\footnotetext{
*Corresponding author:vladimir.andric@ien.bg.ac.rs
}

DOI: $10.5937 /$ sjm16-30877 
modern corporate finance practice; second, the relevance of the Hansen-Sargent prediction formula, not only from the standpoint of expected net present value discounting, but also from the standpoint of time series trend-cycle decompositions, is presented; third, the usefulness of the Beveridge-Nelson decomposition to corporate managers is introduced and discussed, which is especially important since, apart from the study by Chang et al. (2014), this trend-cycle decomposition finds no wide spread practical application in modern corporate finance literature; fourth, building on the recommendations and contributions from Nelson (2008), Gatchev et al. (2010), Dasgupta et al. (2011), Chang et al. (2014), Hendry and Pretis (2016) and Kamber et al. (2018), the paper proposes the real-time decision algorithm on how corporate finance managers can apply these techniques in a unified business framework.

The rest of this paper has the following structure: Section 2 outlines the properties of Laplace transforms. Section 3 derives the equivalence condition between the Beveridge-Nelson decomposition and the Hansen-Sargent prediction formula in continuous time and discusses the potential relevance of techniques mentioned above to corporate finance managers and practitioners. Section 4 concludes.

\section{LAPLACE TRANSFORMS}

Grubbström (1967) was probably the first to show how the present value equation in corporate finance is equivalent to the mathematical notion of Laplace transform used in physics and engineering. Based on Grubbström (1967) observation, Buser (1986) outlines the list of known analytical solutions for present value problems. Finally, Cochrane (2012) shows how Laplace transforms can be used in connection with stochastic processes.

Definition 1: The Laplace Transform of a Stochastic Process (Cochrane, 2012)

If two stochastic, not necessarily stationary, processes, $y_{t}$ and $x_{t}$, satisfy the following relation

$y_{t}=\int_{\tau=0}^{\infty} f(\tau) x_{t-\tau} d \tau$

in which $x_{(t-\tau)}=L^{\tau} x_{t}$, where $L^{\tau}$ is the lag operator and $\tau \in R$, then the Laplace transform of relation (1) is

$F_{f}(D)=\mathcal{L}\{f(\tau)\}=\int_{\tau=0}^{\infty} e^{-D \tau} f(\tau) d \tau$

in which $D, D f(\tau)=\frac{d f(\tau)}{d \tau}$, is the complex number and represents the mean square differential operator which satisfies the following property

$\lim _{\delta \rightarrow 0} E\left\{\frac{x(t+\delta)-x(t)}{\delta}-D x(t)\right\}^{2}=0 . \quad$ The equations (1) and (2) define the relationship between the mean square differential operator $D$ and the lag operator $L^{\tau}$ since $\mathcal{L}\left\{L^{\tau}\right\}=e^{-D \tau}$.

\section{Proposition 1: The Laplace Transform of an Integral Function}

The Laplace transform of an integral function is 
$\mathcal{L}\left\{\int_{s=0}^{\tau} f(s) d s\right\}=\int_{\tau=0}^{\infty} e^{-D \tau}\left[\int_{s=0}^{\tau} f(s) d s\right] d \tau=$

$\frac{F_{f}(D)}{D}$.

\section{Proof of Proposition 1}

The proof follows the expositions outlined in Grubbström (1967) and Buser (1986).

By changing the order of integration, equation (3) becomes

$$
\begin{aligned}
& \mathcal{L}\left\{\int_{s=0}^{\tau} f(s) d s\right\}= \\
& \int_{\tau=0}^{\infty} e^{-D \tau}\left[\int_{s=0}^{\tau} f(s) d s\right] d \tau= \\
& \int_{s=0}^{\infty}\left[\int_{\tau=s}^{\infty} f(s) e^{-D \tau} d \tau\right] d s
\end{aligned}
$$

which is equivalent to

$$
\begin{aligned}
& \int_{s=0}^{\infty}\left[\int_{\tau=s}^{\infty} f(s) e^{-D \tau} d \tau\right] d s= \\
& \int_{s=0}^{\infty} f(s)\left[\int_{\tau=s}^{\infty} e^{-D \tau} d \tau\right] d s
\end{aligned}
$$

and yields

$$
\begin{aligned}
& \int_{s=0}^{\infty} f(s)\left[\int_{\tau=s}^{\infty} e^{-D \tau} d \tau\right] d s= \\
& \int_{s=0}^{\infty} f(s)\left[-\left.\frac{1}{D} e^{-D \tau}\right|_{\tau=s} ^{\infty}\right] d s
\end{aligned}
$$

\subsection{The Beveridge-Nelson decomposition}

The Beveridge-Nelson decomposition decomposes ARIMA (p, 1, q) stochastic process $y_{t}$ into a random walk with a drift component, $x_{t}$, and zero-mean stationary stochastic process, $\varepsilon_{t}$. In particular, following Beveridge and Nelson (1981) and Cochrane (2012), the stochastic process $y_{t}$ can be written as

$y_{t}=x_{t}+\varepsilon_{t}$ 
The relation (8) also holds in period $t+s, s>0$, which produces

$x_{t}=\lim _{s \rightarrow \infty} E_{t}\left(y_{t+s}\right)=y_{t}+$

$y_{t+s}=x_{t+s}+\varepsilon_{t+s}$.

$E_{t}\left\{\sum_{s=1}^{\infty} \Delta y_{t+s}\right\}$

If $s \rightarrow \infty$, then the equation (9), after applying the conditional expectation operator, $E_{t}(\bullet)$, becomes

$\lim _{s \rightarrow \infty} E_{t}\left(y_{t+s}\right)=\lim _{s \rightarrow \infty} E_{t}\left(x_{t+s}\right)+$

$\lim _{s \rightarrow \infty} E_{t}\left(\varepsilon_{t+s}\right)$.

in which $\lim _{s \rightarrow \infty} E_{t}\left(\varepsilon_{t+s}\right)=0$, since, by definition, $\varepsilon_{t}$ corresponds to a zero-mean stationary stochastic process. Also, due to martingale property, $\lim _{s \rightarrow \infty} E_{t}\left(x_{t+s}\right)=x_{t}$, since $x_{t}$ follows a pure random walk with a drift process. Consequently, equation (10) becomes

$x_{t}=\lim _{s \rightarrow \infty} E_{t}\left(y_{t+s}\right)$.

The equation (11) is equivalent to the following representation

$x_{t}=y_{t}+\lim _{s \rightarrow \infty} E_{t}\left[\begin{array}{c}\left(y_{t+1}-y_{t}\right)+ \\ \left(y_{t+2}-y_{t+1}\right)+\cdots+ \\ \left(y_{t+s-1}-y_{t+s-2}\right)+ \\ \left(y_{t+s}-y_{t+s-1}\right)\end{array}\right]$.

due to cancelling of identical $y_{t+s}$ terms and due to $\lim _{s \rightarrow \infty} E_{t}\left(y_{t}\right)=y_{t}$. The equation (12) then becomes
For $\Delta t \rightarrow d t, \Delta y_{t+s} \rightarrow d y_{t+s}$, the continuoustime equivalent of equation (13) is

$$
x_{t}=1_{t}+E_{t}\left\{\int_{s=0}^{\infty} d y_{t+s}\right\}
$$

so it can be stated that

$$
y_{t}-x_{t}=\varepsilon_{t}=-E_{t}\left\{\int_{s=0}^{\infty} d y_{t+s}\right\}
$$

Since $\varepsilon_{t}=y+{ }_{t}\left\{\int_{s=0}^{\infty} d y_{t+s}\right\} \quad$ is, by definition, a zero-mean stationary stochastic process, it must have, as defined in Cochrane (2012), a continuous-time moving average (MA) representation of the form $\int_{\tau=0}^{\infty} f(\tau) \sigma d B_{t-\tau}$ in which $f(\tau)$ corresponds to time-dependent coefficients, $\sigma d B_{t-\tau}$ represents continuoustime error term (shock) with $d B_{t-\tau}$ denoting the increments of standard Brownian motion. For the MA representation to be the firstorder stationary stochastic process, it is sufficient that $f(\infty)=\lim _{\tau \rightarrow \infty} f(\tau)=0 \quad$ which implies decaying, mean-convergent, impulse response function ${ }^{1}$.

\subsection{The Hansen-Sargent prediction formula}

Hansen and Sargent (1981) derive the

\footnotetext{
${ }^{1}$ The necessary and sufficient condition for the second-order stationarity of the MA representation amounts to $\int_{\infty}^{\infty} f^{2}(\tau) d \tau<\infty \quad$ which implies that the variance of the MA form, $\sigma^{2}\left(\varepsilon_{t}\right)=\int_{\tau=0}^{\infty} f^{2}(\tau) \sigma^{2} d \tau$, in which $\sigma^{2} \mathrm{~d} \tau$ represents the variance of standard Brownian motion, does not explode, $\sigma^{2}(\varepsilon t) \rightarrow \infty$ when $\tau \rightarrow \infty$. This condition is not imposed throughout the paper, because it would entail the explicit parametric definition of the $f(\tau)$ coefficients in order to calculate the integral $\int_{\tau=0}^{\infty} f^{2}(\tau) d \tau$.
} 
following prediction formula for the expected discounted value of an arbitrary, not necessarily stationary, stochastic process $y_{t}$

$E_{t}\left\{\int_{s=0}^{\infty} e^{-r s} y_{t+s} d s\right\}=\frac{F_{f}(D)-F_{f}(r)}{r-D} \sigma D B_{t}(16) \quad \varepsilon_{t}=-E_{t}\left\{\int_{s=0}^{\infty} d y_{t+s}\right\}=$

in which $r$ is the discount rate, $1 /(r-D)$ is the lag operator which satisfies $1 /(r-D)=\int_{\tau=0}^{\infty} e^{-(r-D) \tau} d \tau \quad, \sigma D B_{t}$ is a continuous-time shock (error term) in which $D B_{t}=\frac{d B_{t}}{d t} \quad$ denotes the standard Brownian motion, while $F_{f}(D), \quad F_{f}(D)=\int_{s=0}^{\infty} e^{-D s} f(s) d s$, and $F_{f}(r), F_{f}(r)=\int_{s=0}^{\infty} e^{-r s} f(s) d s$, represent respective Laplace transforms.

In the case of the null discount rate, $r=0$, the Hansen-Sargent prediction formula from equation (16) becomes

$E_{t}\left\{\int_{s=0}^{\infty} y_{t+s} d s\right\}=-\frac{F_{f}(D)-F_{f}(0)}{D} \sigma D B_{t}$.

in which $1 / D$ is the lag operator which satisfies $1 / D=\int_{\tau=0}^{\infty} e^{-D \tau} d \tau$.

After applying the differential operator $D=\frac{d(\cdot)}{d s}$, the equation (17) becomes

$\frac{d}{d s}\left\{E_{t}\left\{\int_{s=0}^{\infty} y_{t+s} d s\right\}\right\}=E_{t}\left\{\int_{s=0}^{\infty} d y_{t+s}\right\}=$
After comparing equation (18) with equation (15), it follows that detrended stationary zero-mean component $\varepsilon_{t}$ must satisfy

$\frac{\frac{d}{d s}\left[F_{f}(D)\right]-\frac{d}{d s}\left[F_{f}(0)\right]}{D} \sigma D B_{t}$

Hence, to derive the equivalence condition, the value for $\frac{\frac{d}{d s}\left[F_{f}(D)\right]-\frac{d}{d s}\left[F_{f}(0)\right]}{D} \sigma D B_{t}$ must be obtained.

\subsection{The equivalence condition}

The expression for $\frac{d}{d s}\left[F_{f}(D)\right] \quad$ can be written as

$\frac{d}{d s}\left[F_{f}(D)\right]=\frac{d}{d s}\left[\int_{s=0}^{\infty} e^{-D s} f(s) d s\right]=$

$\int_{s=0}^{\infty} e^{-D s} \frac{d f(s)}{d s} d s=\int_{s=0}^{\infty} e^{-D s} f^{\prime}(s) d s$

Analogously to equation (20), the expression for $\frac{d}{d s}\left[F_{f}(0)\right]$ can be written as

$\frac{d}{d s}\left[F_{f}(0)\right]=\frac{d}{d s}\left[\int_{s=0}^{\infty} e^{-0 s} f(s) d s\right]=$

$\int_{s=0}^{\infty} f^{\prime}(s) d s$.

$-\frac{\frac{d}{d s}\left[F_{f}(D)\right]-\frac{d}{d s}\left[F_{f}(0)\right]}{D} \sigma D B_{t}$ 
Given equations (20) and (21), the equation equation (23) becomes (19) becomes

$\varepsilon_{t}=\frac{\int_{s=0}^{\infty} e^{-D s} f^{\prime}(s) d s-\int_{s=0}^{\infty} f^{\prime}(s) d s}{D} \sigma D B_{t}$

$$
\varepsilon_{t}=\left[\int_{\tau=0}^{\infty} e^{-D \tau}\left[\int_{s=0}^{\tau} f^{\prime}(s) d s-\int_{s=0}^{\infty} f^{\prime}(s) d s\right] d \tau\right] \begin{gathered}
\sigma D B_{t} \\
(26)
\end{gathered}
$$

which is equivalent to

$\varepsilon_{t}=\frac{\int_{s=0}^{\infty} e^{-D s} f^{\prime}(s) d s}{D} \sigma D B_{t}$

$\frac{\int_{s=0}^{\infty} f^{\prime}(s) d s}{D} \sigma D B_{t}$

$\varepsilon_{t}=\left[\int_{\tau=0}^{\infty} e^{-D \tau}\left[f^{\prime} \int_{s=0}^{\infty}\left({ }^{\prime}(s) d s-\int_{s=0}^{\tau} f^{\prime}(s) d s\right)\right] d \tau\right] \underset{(27)}{\sigma D B_{t}}$

and finally yields

The expression $\frac{\int_{s=0}^{\infty} e^{-D s} f^{\prime}(s) d s}{D}$, given the results from proposition 1 , becomes

$\frac{\int_{s=0}^{\infty} e^{-D s} f^{\prime}(s) d s}{D}=\frac{F_{f^{\prime}}(D)}{D}=\mathcal{L}\left\{\int_{s=0}^{\tau} f^{\prime}(s) d s\right\}=$

$\int_{\tau=0}^{\infty} e^{-D \tau}\left[\int_{s=0}^{\tau} f^{\prime}(s) d s\right] d \tau$

The expression $\frac{\int_{s=0}^{\infty} f^{\prime}(s) d s}{D}$, given that $1 / D=\int_{\tau=0}^{\infty} e^{-D \tau} d \tau$, becomes

$$
\varepsilon_{t}=\left[\int_{\tau=0}^{\infty} e^{-D \tau}\left[-\int_{s=\tau}^{\infty} f^{\prime}(s) d s\right] d \tau\right] \sigma D B_{t} .
$$

Since $\int_{s=\tau}^{\infty} f^{\prime}(s) d s=\lim _{s \rightarrow \infty} f(s)-f(\tau)=-f(\tau)$ due to $\lim _{s \rightarrow \infty} f(s)=0$ for the stationary stochastic process $\varepsilon_{t}$, the equation (28) is equivalent to

$\varepsilon_{t}=\left[\int_{\tau=0}^{\infty} e^{-D \tau} f(\tau) d \tau\right] \sigma D B_{t}=$

$\left(\int_{\tau=0}^{\infty} e^{-D \tau} d \tau\right)\left(\int_{s=0}^{\infty} f^{\prime}(s) d s\right)=$

$\int_{\tau=0}^{\infty} e^{-D \tau}\left[\int_{s=0}^{\infty} f^{\prime}(s) d s\right] d \tau$.

$\left[\int_{\tau=0}^{\infty} e^{-D \tau} f(\tau) d \tau\right] \sigma \frac{d B_{t}}{d t}$

After inserting the expressions from which yields equations (24) and (25) into equation (23), 
$\varepsilon_{t}=\int_{\tau=0}^{\infty} e^{-D \tau} f(\tau) \sigma d B_{t}=\int_{\tau=0}^{\infty} L^{\tau} f(\tau) \sigma d B_{t}=$

$\int_{\tau=0}^{\infty} f(\tau) \sigma d B_{t-\tau}$

producing the MA representation for the stationary zero-mean stochastic process $\varepsilon_{\mathrm{t}}$ defined in section 3.1. which finally concludes the proof of the equivalence condition.

\subsection{The discussion of results}

The continuous-time results presented in subsections 3.1., 3.2. and 3.3. can be used for real-time business decision making since continuous-time Laplace transforms correspond to Z-transform in discrete time. Cochrane (2012) shows how the equivalence condition between the Hansen-Sargent prediction formula and the BeveridgeNelson decomposition holds in discrete time as well, given that the discount rate is set equal to one. Consequently, corporate finance officers can use the following decision-making algorithm in making investment and finance decisions: 1) according to the Hansen-Sargent prediction formula, rank alternative investment projects given their expected net present values; 2) collect the time series data of sources and uses of cash flow streams from investment projects ranked in step 1 by using the following cash flow accounting identity: Cash Flow $_{t}$ Investments $_{t}+\Delta$ Cash Balance ${ }_{t}{ }^{+}$

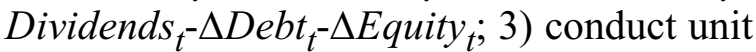
root tests along with ARIMA (p, d, q) BoxJenkins methodology to determine the order of integration of time series of cash flow streams, Cash Flow ${ }_{t}$, calculated in step $2^{2}$; 4)

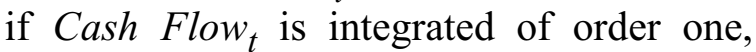
Cash Flow ${ }_{t} I$ (1), decompose the cash flow stream to the permanent and transitory component via Beveridge-Nelson filter, given the recommendations outlined in Kamber et al. $(2018)^{3}$; 5) following the advice of Nelson (2008), regress via ordinary least squares (OLS) the change in the cash flow stream, $\Delta$ Cash Flow , on a lagged cyclical cash flow component, Cash

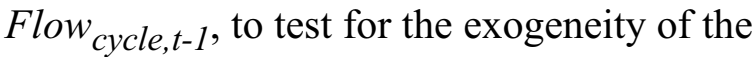
cyclical component given the future cash flow growth opportunities 4 ; 6) if Cash Flow $_{\text {cycle } t-1}$ is orthogonal ${ }^{5}$ to $\Delta$ Cash Flow , estimate the system of OLS cash flow sensitivity regressions of the form $y_{t_{(5 \times 1)}}=\alpha_{0(5 \times 1)}+\alpha_{1_{(5 \times 1)}}$ Cash Flow $_{\text {cycle }, t}+$ $\alpha_{2(5 \times n)} X_{t_{(n \times 1)}}+\epsilon_{t_{(5 \times 1)}} \quad$ in which $y_{t_{(5 \times 1)}}$ is a column vector of dependent variables (Investments $_{t}, \Delta$ Cash Balance $_{t}$, Dividends , $\Delta$ Debt $_{t}, \Delta$ Equity $\left._{t}\right), \quad X_{t(n \times 1)} \quad$ is a column vector of business-related control variables, and $\epsilon_{t_{(5 \times 1)}}$ is a column vector of error terms which must satisfy the assumptions of classical multiple OLS linear regression model 6 ; 7) given the estimated vectors of

\footnotetext{
2For practical step-by-step details of the Box-Jenkins ARIMA (p, d, q) methodology, see Hendry and Pretis (2016).

${ }^{3}$ Kamber et al. (2018) derive the Beveridge-Nelson filter consistent with the low signal-to-noise ratio. In comparison to the original Beveridge-Nelson decomposition, the Beveridge-Nelson filter of Kamber et al. (2018) has three distinctive advantages: 1) it accounts for potential structural breaks; 2) it produces accurate out-of-sample forecasts; 3 ) it requires fewer estimation revisions as new data comes in, which is especially important from the standpoint of real-time business conduct.

${ }^{4}$ Nelson (2008) documents that the cycle component should contain little information about future growth beyond short-term momentum.

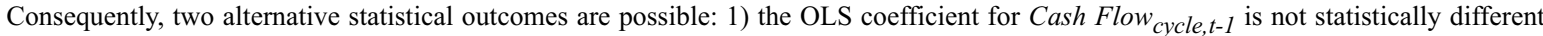

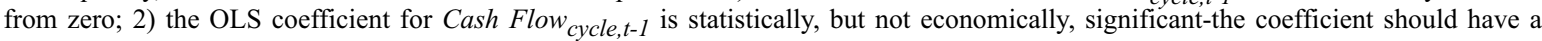
negative value close to zero, since, for the negative cycle component, the recovery should have an above-average future growth rate and vice versa.

$5_{\text {If Cash Flow }}$ cycle,t-1 is not orthogonal to $\Delta$ Cash Flow $_{t}$, the decomposition of the cash flow stream, Cash Flow , should be obtained for the alternative value of the signal-to-noise ratio, which must be consistent with the exogeneity of the cyclical cash flow component.

${ }^{6}$ Chang et al. (2014) show how OLS, equation by equation, estimates are equivalent to the seemingly unrelated regressions (SUR) estimates since each equation in the system has its dependent variable followed by the set of identical explanatory variables. Moreover, the authors show that when the cash flow sensitivities are estimated within the OLS framework, the coefficients of the cycle component satisfy the adding-up constraint, i.e., their sum equals to one, provided that the cash flow identity, Cash Flow ${ }_{t} \equiv$ Investments $_{t}+\Delta$ Cash Balance $_{t}^{+}$ Dividends $_{t}-\Delta$ Debt $_{t}-\Delta E q u i t y$, , implicitly holds in the data set under investigation.
} 
coefficients $\alpha_{0}, \alpha_{1}$ and $\alpha_{2}$, formulate and update in real-time specific investment and financing policies ${ }^{7}$.

\section{CONCLUSION}

As Brunnermeier and Sannikov (2016) point out, the continuous-time framework is mathematically more tractable and might conceptually be a closer representation of reality. This framework's problem lies in estimating continuous-time models since these econometric techniques are far more complex in terms of computational intensity. For the techniques discussed in this paper, this is not the case since the equivalence condition between the Hansen-Sargent prediction formula and the BeveridgeNelson decomposition also holds in discrete time. In other words, corporate finance managers and practitioners can use these techniques on real-time historical data to differentiate between permanent and transitory shocks to cash flows and to estimate various cash flow sensitivities crucial for making investment and financing decisions.

\section{Acknowledgements}

The Ministry of Education, Science, and Technological Development of Serbia financially supported this research.

\section{References}

Beveridge, S., \& Nelson, C. (1981). A New Approach to Decomposition of Economic Time Series into Permanent and Transitory Components with Particular
Attention to Measurement of the Business Cycle. Journal of Monetary Economics, 7 (2), 151-174.

Brunnermeier, M., \& Sannikov, Y. (2016). Macro, Money and Finance-A Continuous Time Approach. National Bureau of Economic Research. NBER Working Paper No. 22343. Retreived from https://www.nber.org/system/files/working_ papers/w22343/w22343.pdf

Buser, S. (1986). Laplace Transforms as Present Value Rules: A Note. Journal of Finance, 41 (1), 243-247.

Chang, X., Dasgupta, S., Wong, G., \& Yao, J. (2014). Cash-Flow Sensitivities and the Allocation of Internal Cash Flow. The Review of Financial Studies, 27 (12), 36283657.

Cochrane, J. (2012). Continuous-Time Linear Models. Foundations and Trends in Finance, 6 (3), 165-219.

Dasgupta, S., Noe, T.H., \& Wang, Z. (2011). Where Did All the Dollars Go? The Effect of Cash Flows on Capital and Asset Structure. The Journal of Financial and Quantitative Analysis, 46 (5), 1259-1294.

Gatchev, V.A., Pulvino, T., \& Tarhan, V. (2010). The Interdependent and Intertemporal Nature of Financial Decisions: An Application to Cash Flow Sensitivities. The Journal of Finance, 65 (2), 725-763.

Grubbström, R. (1967). On the Application of the Laplace Transform to Certain Economic Problems. Management Science, 13 (7), 558-567.

Hansen, L.P., \& Sargent, T.J. (1981). A Note on the Wiener-Kolmogorov Prediction Formulas for Rational Expectations Models. Economic Letters, 8 (3), 255-260.

Hendry, D. \& Pretis, F. (2016). All Change! The Implications of NonStationarity for Empirical Modelling, Forecasting and Policy. Oxford Martin

\footnotetext{
${ }^{7}$ The real-time updating of estimated OLS coefficients of cash flow sensitivities is crucial since state-of-the-art theoretical corporate finance models do not provide a unique answer about the size and sign of the coefficients mentioned above. The same criticism extends to modern empirical studies in this area of corporate finance: Gatchev et al. (2010) find no statistically significant relationship between internally generated cash flows and investments. However, Dasgupta et al. (2011) find a positive statistical response of investments two years after the cash flow shock.
} 


\section{ЛАПЛАС, ХАНСЕН-САРЏЕНТ И БЕВЕРИЏ-НЕЛСОН НАПОМЕНА О ЈЕДИНСТВЕНОЈ ПОСЛОВНОЈ ПРИМЕНИ}

\section{Владимир Андрић, Сања Ненадовић}

\section{Извод}

У раду се изводи услов еквиваленције између Бевериџ-Нелсонове декомпозиције и ХансенСарџентове формуле предвиђања у континуираном времену користећи Лапласову трансформацију. Представљени резултати показују како је Хансен-Сарџентова формула предвиђања релевантна не само за дисконтовање садашње вредности, већ и за декомпозицију готовинских токова на тренд и цикличну компоненту у корпоративним финансијама.

Кључне речи: Бевериџ-Нелсонова декомпозиција, Хансен-Сарџентова формула предвиђања, Лапласове трансформације, новчани токови

School Policy Paper Serires. Retreived from https://ssrn.com/abstract=2898761.

Kamber, G., Morley, J., \& Wong, B. (2018). Intuitive and Reliable Estimates of the Output Gap from a Beveridge-Nelson Filter. The Review of Economics and Statistics, 100 (3), 550-566.

Nelson, C.R. (2008). The BeveridgeNelson Decomposition in Retrospect and Prospect. Journal of Econometrics, 146 (2), 202-206. 